\title{
Research on the Internal Management Communication of Enterprises Based on Wanda Film
}

\author{
Bowen Sun ${ }^{1, *}$ \\ ${ }^{1}$ School of music and dance, Jiangxi University of Technology, Nanchang, Jiangxi, China \\ *Corresponding author. Email:guanghua.ren@gecacademy.cn
}

\begin{abstract}
Since the reform and opening up, my country's private enterprises have developed rapidly and their number has increased sharply. With the rise of private enterprises, the brain drain has become an urgent problem to be solved. Among the different causes of this problem, communication problems are one of the main defects that hinder the development of the company. For sustainable and healthy development, companies need to find reasonable solutions to deal with this situation. This article will combine relevant theoretical knowledge and case analysis to make a more comprehensive summary and analysis of the management communication problems of private enterprises. As far as case analysis is concerned, the public data of the case company is collected from the Internet, and the advantages and disadvantages of the case company in communication management are analyzed in detail based on the data. After that, further solutions and suggestions were put forward accordingly, such as shaping diversified communication channels and improving management's awareness of the importance of communication. These results clarify that when there is a problem in the internal communication management of an enterprise, communication is often both the cause of the problem and the means to solve the problem. Therefore, communication is very important to the management of the enterprise.
\end{abstract}

Keywords: Management communication, Private Enterprise, Obstacles, Countermeasures.

\section{INTRODUCTION}

Currently, communication is one of the most common and effective ways of exchanging information. Meanwhile, communication plays an indispensable role in business management, which exchanges and integrates information effectively. Management communication is just like the relationship between people and food/water for business management. It is not only the exchange of language and information, but also a kind of development and extension based on communication. In the meantime, management communication is the development of the original communication foundation, the collective and the individual as well as the superior and the subordinate. To meet the challenges and opportunities in the market, companies need to maintain their competitive advantages and customer loyalty as well as expand the market. A large part of them must rely on internal and external communication in corporate management. Management communication is a key factor for an enterprise to enhance its overall strength and an indispensable requirement for its internal development. Nowadays, facing the information era, in order to give full play to the enterprise's potential, enterprise managers must communicate effectively with grassroots employees, though enterprise development has strong flexibility.

There are plenty of private enterprises in our country, where some of them face management communication problems: individual employees cannot get enough trust and respect, and communication between superiors and subordinates cannot be effective. The management of private enterprises is mostly composed of family members as employees outside are distrustful. These problems may cause the loss of talents within the enterprise, or will lose a lot of valuable suggestions. Besides, it will also affect the construction of employees within the enterprise.

This article mainly analyzes the communication problems existing in business management and the reasons for the communication problems. For better illustration, the case study method and theoretical research method are utilized to conduct research. Besides, some countermeasures and methods are proposed to solve the communication problems, e.g., shaping the diversity of communication channels, 
improving management's awareness of the importance of management communication, etc.

The rest of the paper is organized as following: the Section 2 presents a literature review; Section 3 gives an overview of the related concepts of communication and management communication. Section 4 demonstrates a case study for Wanda Film Co., Ltd. to analyze the status quo of internal management communication and the existing problems. The Section 5 discusses the measures to reduce the management communication problems of private enterprises, and puts forward some suggestions to help efficient communication. The Section 6 is enlightenment and the Section 7 gives a brief summary.

\section{LITERATURE REVIEW}

The literature cited below is very consistent with the content of this thesis, mainly for the study of communication management obstacles, communication management problems, and the positive role of communication management in corporate transformation.

Liu [1] found that small private enterprises in southern Fujian have certain communication and management barriers. He took Quanzhou Guanshun Medical Devices Co., Ltd. as an example, obtaining certain results. Besides, he summarized some small private enterprises in southern Fujian.

Zou [2] studied the positive role of communication management in company transformation. He put forward some valuable suggestions: (1) Bring communication management into transformation project management. (2) Obtain the support of senior leaders. (3) Make full use of the power of middle-level leaders. (4) Establish a network of change facilitators among grassroots employees. (5) Choose visual communication channels. (6) Establish a full-time position for change management and recruit change management experts.

Scholar Pan [3] took a company as an example to study the problems and countermeasures in the company's management communication. Pan Yue scholars learned about the current situation of company D's communication management through questionnaire surveys, and summarized the five main issues of company D's communication management based on the status quo. Pan Yue scholars not only raised questions, but also used literature research methods and comparative research methods at the end of the article. Summarized the solution to the communication management problem of D company.

Scholar Fu [4] took a Company as an example to study the communication management of international project teams (2014-05-05). Fu Feifeng scholars believe that establishing a good communication mechanism for cross-cultural teams is inseparable from a smooth communication channel inside and outside the project. The barrier effect of language will become weaker and weaker, i.e., the role of communication between internal and external will become greater and greater.

Jiang [5] investigated the communication management of small and medium-sized $R \& D$ projects. The three characteristics of $R \& D$ project communication management are summarized. The the conclusions drawn are clear and systematic, based on the research results of conventional project communication management theory, combined with the influence of team member behavior and leadership behavior. Whereas, there are still some shortcomings in the research, e.g., insufficient depth and comprehensiveness.

Sun [6] uses a combination of theoretical research and case studies to analyze corporate project management issues. It draw a conclusion based on the combination of theory, starting from practice, giving a certain degree of practice plan summary and applied research 。

$\mathrm{Fu}$ [7] chooses the communication management of the new generation of employees as the key content. Through the analysis of the unique work characteristics of the new generation of employees, combined with their personality, social background, and the specific practices of Guangzhou Railway Company and other companies, a new generation of new employees management strategy is proposed. Since it is mainly used for domestic project communication management, it mainly analyzes, reads, summarizes and summarizes domestic documents, while foreign documents are rarely cited and collected.

In this study, more representative examples will be used for analysis. Besides, it will overcome shortcomings by learning from the above-mentioned literature to, and propose countermeasures for some common communication management problems.

\section{OVERVIEW OF RELATED CONCEPTS}

This section described some theoretical concepts related to management including: the concept of private enterprises as well as the concepts of communication and management. Based on the related concepts and the related literature, the reasons of communication barriers, and the harmful of the communication barriers will be demonstrated. At the end of the section, the relationship between communication management and corporate culture is discussed.

\subsection{Private Enterprise}

Private enterprise is a proper name based on the type of enterprise or company. The difference from stateowned enterprises lies in the regulation of policies and the scope of capital concentration. When the proportion of non-state-owned investment is greater than $50 \%$, the enterprise is a private enterprise, while it is a state-owned 
enterprise if the proportion of state-owned investment is greater than 50. The definition of private enterprise is not unique in economics. One argument is that a private enterprise is a legal person economic entity that is invested, operated, and profited by private individuals, and whose operating risks are borne by private individuals. Private enterprises can also be divided into state-owned private enterprises and private enterprises. First of all, the property rights of state-owned private enterprises belong to the state, and the leaser must raise funds, bear risks, and be responsible for its own profits and losses. The private sector refers to individual enterprises and private enterprises. Generally, individual enterprises are generally small in scale and simple in enterprise structure. It is funded by individuals and operated by the owner independently, and the owner also enjoys all the benefits of the enterprise. The private enterprise refers to a profitable economic organization that is invested by or controlled by a natural person and is based on hiring labor.

\subsection{Communication and corporate culture}

In this part, the concept of communication is explained primarily, and then the connection between communication and management is demonstrated through the understanding of related concepts. Subsequently, the importance of the combination of communication and management will be emphasized.

Communication refers to the meaning of contact, communication, exchange and exchange, which has broad sense and narrow sense. Broad sense refers to the communication process of thoughts, opinions, beliefs, opinions, feelings, desires and information between two or more people. Narrow sense refers to the process of transmitting a kind of information to the recipient of the information through a certain way. In both broad or narrow sense, the communication process contains three elements: the sender of the information, the receiver of the information, and the content of the information (which can be objective facts or personal subjective feelings).

Communication plays an important role in the management work. (1) Communication is the basis and starting point of scientific management. It is necessary for any organization to formulate/implement policies, determine plans, scientifically organize as well as command and coordinate the production or work of its various departments. Little work that runs through all aspects. (2) Communication is an indispensable part of meeting the psychological needs of employees, improving interpersonal relationships, as well as increasing the morale and productivity of employees. (3) Communication is an important form of employee participation in management and an important means of changing employee behavior. There are many forms of communication, which can be classified from different perspectives. From the perspective of the organizational system, it can be divided into formal communication and informal communication. With regard to the perspective of the sender and receiver of information, it can be divided into one-way communication and two-way communication. As for the perspective of communication, it can be divided into downward communication, upward communication, parallel communication and diagonal communication. From the perspective of communication, it can be divided into oral communication and written communication, etc. [9].

Experts and scholars have more than 200 definitions of corporate culture. A typical example is the American management scientist Daimler Kot. The definition he gave refers to individuals from different countries, races, cultures, backgrounds, regions, ages, genders, educational backgrounds, etc. Shared corporate environment and culture. It includes the same work philosophy, goals, spirit, habits, methods, and even similar outlook on life, values, world outlook, etc.. It is the corporate culture that can bring many employees with significant individual differences to work together [10].

Corporate culture is always inextricably linked to specific regions and national cultures, which results in various unique corporate cultures for companies in different regions. At the same time, corporate culture is also a very special part of human culture. The particularity of corporate culture is different from other cultures of human beings. Corporate culture is only produced through the economic activities of enterprises. Besides, corporate culture is an indispensable part of its development for a company, which has many benefits to corporate development.

\subsection{Communication barriers in corporate management}

Private enterprises are mostly managed by family members composed of management, which will cause the enterprise to lose talents, and at the same time, employees who are not family members will not be reused in the enterprise. As a consequence, employees feel that they do not receive their deserved respect from the employees and the company. Managers are also unable to communicate effectively, which will also lead the company to lose a lot of valuable advice. Thus, it is not conducive to the development of the company. In addition, there may be complicated nepotism in private enterprises, which has caused many communication barriers. For example, the company cannot treat all employees equally, or the suggestions of non-family members are not taken seriously due to nepotism. The main reason why company management cannot communicate well. Meanwhile, due to the strong selfesteem and strong hierarchical concept of the manager the manager himself is unwilling to be opposed by 
employees, even if there is no nepotism in the enterprise, as a manager of the enterprise.

The managers of most companies do not formulate relevant management policies for communication. Therefore, most internal communication in the company relies on the communication methods and skills of the two parties. Besides, the communication skills and methods of the two parties may be considered too daily life, which has a certain impact on the effectiveness of communication.

The weak management of internal communication channels in enterprises is due to various subjective or objective reasons, resulting in weak management of internal communication channels in the enterprise. Hence, the internal management communication channels of the enterprise are single, the efficiency of information transmission is low, and some information cannot be effectively transmitted, i.e., it forms Communication barriers.

\subsection{The relationship between corporate culture and employee communication}

Corporate culture occupies a very important position in the daily management of a company. The well-known American corporate culture research scholar Biddes said in his book "Heart to Success": In today's business wars, competition is fierce and full of chaos, like a battlefield. The biggest bottleneck faced by enterprises in management is the soft case, and an important part of it is culture [8]. Although there are still many opinions about corporate culture in academia, its important role cannot be ignored in corporate management, e.g., guiding function, cohesive function, coordination function, and restraint function.

First of all, as far as the guidance function is concerned, the corporate culture enables the formation of the same value concept within the enterprise, thereby guiding all employees to work together on the common value concept. Thereby, the company can achieve better development. The relationship between corporate culture and employees does not end there. Corporate culture is a very special member of human culture, though it is not created by a certain company or its employees. However, it has a close relationship with every company and every employee. Besides, the dissemination and formation of corporate culture are inseparable from communication.

As the most important communication method for human beings, communication can spread not only information but also emotions and consciousness. Moreover, corporate culture is not only a kind of internal norms and publicity to the outside of the company, but more importantly, it is common to all employees. Wealth and corporate culture are always formed by all employees in the company, which is a positive attitude and a spirit and attitude that you want to promote. The cohesive function and coordination function of corporate culture will also be reflected through the communication between employees. First of all, because of the same value concept, employees also have a common goal, which encourages the employees work together. With more effective communication, the interpersonal relationship within the enterprise will be harmonious, i.e., the coordination function of the corporate culture is also reflected.

As for the restraint function, people always hope to be accepted by the environment in which they live, and the corporate culture is the prerequisite for new employees to be accepted by the new working environment. The corporate culture of each company is unique, which carries the will and behavior recognized by all employees. The same way of communication within the company is included, and communication has become one of the important ways to spread the corporate culture. People in the company continue to shape the corporate culture through communication, and to pass on the corporate culture between new and old employees. Outside the enterprise, people use language communication to shape the corporate image, change people's stereotypes of the enterprise, and enable the enterprise to develop better. Corporate culture includes communication and also enables corporate culture to have better development and more functions simultaneously. The two complement each other and achieve each other.

\section{CASE ANALYSIS OF WANDA FILM CO., LTD.}

Since the emergence of private enterprises in the early stage of reform and opening up, a huge number of private enterprises have emerged in China. For better illustration a case study is carried out. The method enables this thesis to get more rigorous conclusions. Take Wanda Film Co., Ltd., a subsidiary of Wanda Group, which is very successful and well-known in China, as an example for research and analysis.

Wanda Film Co., Ltd. was established in 2005 belonging to Wanda Group. According to statistics, as early as June 30, 2014, it had 150 opened theaters in more than 80 cities across the country, and it achieved a revenue of 4.023 billion yuan in 2013. In 2014, Wanda Cinemas accounted for $14.5 \%$ of the country's box office share [11].

Wanda Film \& Television Co., Ltd. is a very successful private enterprise in China. As a private enterprise, it has both advantages and disadvantages. So far, Wanda Co., Ltd. has successfully released one after another well-known movies and has achieved a lot of achievements. As early as 2010, Wanda Film and Television Co., Ltd. became the cinema with the most screens in Asia. In 2012, it was also known as China's 
first cinema chain with a box office of over 2 billion yuan. The bigger and bigger the company, the better its earnings, and the success of the company is not just because of the unique vision of its managers. However, the company does have its own advantages in company management. Firstly, it belongs to Wanda Group, which allows it to have enough management experience to absorb. Secondly, as a private enterprise, there is no nepotism among the internal management of the company, i.e., the company have more useful suggestions to be adopted than other companies with serious nepotism. This is one of the reasons for the company's continuous growth. Whereas, it also faces certain problems. According to the data, the company has 12 management personnel. However, in terms of the company's size and the number of employees, the number of management personnel is extreme small. Some communication problems have arisen because of the wide distribution of the company and the large number of grassroots employees. If the management does not pay attention to the company's communication management, it will lead to conflicts between the company's grassroots employees and managers. Besides, the work information cannot be effectively communicated and feedback, which will lead to more serious problems. Perhaps most of the private enterprises do not have a strong background like Wanda Film and Television Co., Ltd., but the communication management problems that exist do exist in most private enterprises. Therefore, the company's existing communication management problems are representative and have a certain reference significance.

\section{COUNTERMEASURES TO REDUCE COMMUNICATION PROBLEMS}

In order to reduce the occurrence of communication issues in business management, management should improve the management's awareness of the importance of communication management. Only efficient and equal communication can reduce the frequency of information dissemination and avoid information distortion. On the one hand, various communication channels ought to be provided, so that the information can reduce some distortions due to objective factors. On the other hand, internal communication policies should be formulated to make internal communication within the enterprise simple and efficient

\subsection{Shaping diversified communication channels Diversified}

Communication channels can ensure sufficient information transmission methods, and effective communication between the company's superiors and superiors. Communication is the dissemination of information and emotions, which requires a certain way. A good method can not only effectively improve communication efficiency, but also reduce the frequency of information transmission, thereby ensuring the accuracy of information.

First of all, most companies do not have a policy of communicating within the enterprise, which also leads to poor management of corporate communication channels. As a result, it makes most communication channels unusable. At the same time, communication channels can be divided into formal channels and informal channels, upward and downward communication channels, and horizontal and vertical communication channels. Modern enterprises should establish various communication channels and effectively manage communication channels.

Most modern enterprises, especially private enterprises, have nepotism. Because of this family-style business model, non-family employees have no right to speak in the company, and since there is only a single communication channel within the company, the suggestions made are not only bad.

In this case, for a long time, the company will not only lose talents, but also many valuable suggestions for the company. This is not only detrimental to the company's development, but even has a very serious impact on the company. When shaping diversified structural channels, one must pay attention to the shaping of both formal and informal channels. The two different communication channels not only provide more possibilities for internal communication within the enterprise, but also provide more communication methods for employees. Informal communication channels can also alleviate people's worries to a certain extent. Companies collect more suggestions. The company enables the company to carry out healthy and long-term development.

Meanwhile, corporate department coordination and teamwork awareness are required. It is also one of the indispensable important conditions for companies to shape diversified communication channels. The larger the enterprise, the more levels of enterprise management, and the higher the distortion rate in the transmission of information. Furthermore, good department coordination and a good sense of teamwork can make diversified communication channels more efficient and complete.

\subsection{Improve management's awareness to communication}

Communication management requires not only the cooperation of employees but also the attention of the company's management. The management's awareness of the importance of communication in business management should not only lie in the exchange of information, but also in the mutual respect and listening of the employees of the enterprise. There is no doubt that every employee of an enterprise wants to be respected and valued in the enterprise, and his talents can be displayed and recognized. However, because of the 
manager's too strong self-esteem and strong hierarchical concept, employees cannot get the feeling of being respected and valued. On the other hand, managers have ideological deviations and value external communication with customers, suppliers, distributors, etc., while ignoring internal communication within the enterprise. The communication method is single, most of them are one-way communication, and most of the tasks are the main task, and the equal two-way communication cannot be carried out. In the end, managers may lack certain communication skills. Managers are often only concerned with work performance and neglect to be people-oriented in communication.

In order to enable the company to develop well, the management should change its perception of communication management. It is necessary to be aware of the importance of communication in business management, and strive to make changes. Equal communication between management and employees not only helps the company obtain more valuable suggestions, but also makes employees feel respected and valued, thereby enhancing employee loyalty. In the meantime, it can also reduce the management level in the enterprise, i.e., the probability of distortion when the information is transmitted within the enterprise is reduced. Besides, the timeliness of the information is improved to a certain extent.

Therefore, enterprise management needs to be aware of the importance of communication management. In addition, the upper and lower levels of the enterprise can conduct equal and effective communication, so that the aspirations of the upper and lower levels are the same, and the company can develop better.

\subsection{Formulate internal communication policies}

Adhering to the principle of mutual respect and equal communication, the norms include the communication methods between management staff and grassroots employees. As the saying goes, "There is no rule, there is no roundness". Only the same rules are made for all employees regardless of their positions. A sense of respect can be obtained, and respect is an indispensable prerequisite for equal exchanges. All employees must first formulate relevant policies to standardize the communication methods of all employees. Thus, the management employees are not "above" but communicate with grass-roots employees on an equal footing. This can not only improve the efficiency of information transmission, but also increase the loyalty of employees. Therefore, formulate a relevant communication policy is indispensable for business management.

\section{ENLIGHTENMENT}

Most private enterprises have certain communication management problems. Even well-known private enterprises in China also have some problems, e.g., serious nepotism in the company, lack of communication channels within the company, and family management in the company. In order to reduce the occurrence of communication management problems within the enterprise.

Communication management is one of the important factors for the company's sustainable and healthy development. Only when the company's internal communication management issues are handled properly, the company's internal relationships will be harmonious, information can be effectively disseminated, and talents and useful suggestions will not be lost. In this way, the importance of communication management position is underlined. Good communication can make the company continue to develop healthily, i.e., it can make the company's internal unity, atmosphere harmonious and enjoyable. It is believed that such a company is not only the company that all employees hope, but also a continuous healthy company.

\section{CONCLUSION}

In summary, this article takes Wanda Film and Television Co., Ltd. as an example to investigate the management communication problems existing in private enterprises. In addition to analyzing the communication problems in business management, it also summarizes some related theories, and focuses on the analysis of communication barriers in business management. Afterwards, some suggestions are puts forward accordingly on how to reduce the management communication problems in private enterprises.

Based on the analysis, it is found that most private enterprises have certain communication management problems.In order to reduce the occurrence of communication management problems within the enterprise, this article proposes some countermeasures based on case studies and understanding of related concepts: (1). Create diversified communication channels; (2). Improve the company's senior level of awareness of the importance of communication management; (3). Strengthen the cultivation of communication skills for company employees; (4). Formulate and improve communication policies within the company.

This article also has some shortcomings. For example, the information collection of selected company in case analysis is insufficient, which leads to certain limitations in the subsequent analysis. In the future, there may be more problems in communication management due to the development of corporate culture and society. 
It is hoped these results will offer a guideline for further research based on the same topic.

\section{REFERENCES}

[1] Liu Chunxiao Master Research on Management Communication Barriers of Small Private Enterprises in Southern Fujian Taking Quanzhou Guanshun Medical Devices Co., Ltd. as an example, Huaqiao University,2013-12-09. DOI:https://www.cnki.net/

[2] Zou Shenglin, Master The Positive Role of Communication Management in Enterprise Reform, Human Resources, 2020-12-23. DOI:https://www.cnki.net/

[3] Pan Yue, Master Research on Management Communication Problems and Countermeasures of D Company, Dalian University of Technology, 2013-09-16. DOI:https://www.cnki.net/

[4] Fu Feifeng, Master Communication Management of International Project Team — Taking Company B as an example, Zhejiang University of Technology, 2014-05-05. DOI:https://www.cnki.net/

[5] Jiang Yubao, Master Research on Communication Management of Small and Medium R\&D Projects, Tsinghua University, 2011-05-01. DOI:https://www.cnki.net/

[6] Fei Sun. Master Research on Enterprise IT Project Management_-Taking L Company as an Example, Beijing Jiaotong University, 2014-0601. DOI:https://www.cnki.net/

[7] Fu Jingjing Master Research on Communication Management of New Generation Employees of Guangzhou Railway Company, Shihezi University, 2014-05-01. DOI:https://www.cnki.net/

[8] Hu Hao. Master Hainan University, 2014-12-01. DOI:https://www.cnki.net/

[9] A dictionary of new terms in the new era

[10] Li Jianshu.Master Research on Countermeasures of Ideological and Political Work in State-owned Enterprises. Southwest Petroleum University Master's Thesis. 2012-06-01. DOI:https://www.cnki.net/

[11] People's Daily Online, 2017-11-25. DOI:http://www.people.com.cn/ 